\title{
Mística y exégesis en la filosofía de Plotino ${ }^{1}$
}

Mysticism and Exegesis in the Philosophy of Plotinus

\author{
Gabriel MARTINO \\ Universidad de Buenos Aires \\ gabriel.filosofia@hotmail.com
}

\begin{abstract}
Resumen: Dos de los elementos constitutivos de la filosofía de Plotino son la mística y la exégesis de sus predecesores. Estos aspectos de su pensamiento, sin embargo, son interpretados de modos diversos por los especialistas. A raíz de esto, en el presente trabajo intentamos poner de manifiesto y explicar la exégesis plotiniana de algunas ideas de los pensadores medioplatónicos y evaluamos la impronta que junto con las experiencias místicas tiene en su concepción metafísica. Ofrecemos, por último, una interpretación de la relación que la mística y la exégesis presentan en las Enéadas y reconsideramos las lecturas de los estudiosos sobre este tema.
\end{abstract}

ABSTRACT: Two of the constitutive elements of Plotinus' philosophy are mysticism and the exegesis of the philosophers that preceded him. These two aspects, however, are interpreted in different ways by scholars. Due to these facts, in the present paper we try to show and explain Plotinus' exegesis of some Middle Platonic ideas. Furthermore, we evaluate the impact that these ideas together, with his mystical experiences, had on his metaphysical doctrine. We offer, in the last place, an interpretation of the relationship that mysticism and exegesis have in the Enneads, reconsidering the way in which scholars understand it.

PALABRAS ClAVE: neoplatonismo, platonismo medio, metafísica.

KEY WORDS: Neoplatonism, Middle Platonism, Metaphysics.

RECIBIDO: 22 de marzo de 2012 • ACEPTADO: 30 de enero de 2013.

La obra filosófica de Plotino posee un carácter distintivo y, en cierto modo, único, que ha llevado a los intérpretes a considerarla un punto de inflexión ${ }^{2}$ en la historia de la filosofía. Su pensamiento ha sido entendido como culminación de una tradición ${ }^{3}$ y, a la vez, como punto de partida de un nuevo modo de reflexionar y de experimentar el mundo. ${ }^{4}$ Dos

${ }^{1}$ El presente artículo es una adaptación de una ponencia presentada en el II Simpósio da Sociedade Ibero-Americana de Estudos Neoplatônicos (SIAEN) el 23 de mayo de 2011 en Niteroi, Brasil.

2 Véase Eon 1970, p. 252. También Runia 1999, p. 152.

${ }^{3}$ Véase Armstrong 1973, p. 281.

${ }^{4}$ Respecto de Plotino como iniciador de un nuevo período en la historia de la filosofía véase, por ejemplo, Armstrong 1967, p. 195; Wallis 2002, p. 1, o también Rist 1967 , p. 213, quien se refiere a Plotino como el padre de la mística occidental. 
de sus aspectos constitutivos que han motivado tales interpretaciones son la exégesis plotiniana de los pensadores que le preceden y la mística. Es posible, en efecto, encontrar en Plotino un pensador que logró ofrecer una síntesis de la filosofía de sus antecesores, sistematizando los principales problemas sobre los que el platonismo discutió por más de seis siglos. En este sentido, nuestro pensador podría ser considerado como un punto culminante en la tradición platónica. Por otra parte, hallamos en las Enéadas una cantidad considerable de discursos en los que se caracteriza una serie de experiencias con la cima de la realidad inteligible. La intensidad de las exposiciones sobre estas experiencias "místicas", a su vez, constituye para la historia de la filosofía una nueva tendencia, no sólo discursiva, sino también disposicional, respecto del modo en que los filósofos platónicos experimentaban el mundo en sus diversos aspectos.

Ahora bien, si resulta evidente que la mística y la exégesis son dos de los aspectos constitutivos de la filosofía de Plotino, no es en absoluto manifiesta la relación que ambas poseen en el pensamiento eneádico ni, mucho menos, la función creativa e impulsora que cada una de ellas ejerce en el conjunto de la doctrina plotiniana. ${ }^{5}$ Tanto es así que las posiciones de los especialistas en cuanto a esta relación oscilan entre, por un lado, atribuir a la mística un papel de superior importancia respecto de la exégesis y, por otro, desestimar el papel de la mística para explicar cualquier elemento de la filosofía de Plotino. Szlezák es un exponente de esta primera tendencia interpretativa, y, a su entender, la tradición filosófica y la exégesis erudita plotiniana no pueden ser puestas en comparación con la presencia efectiva de lo Uno que, según Plotino, el hombre experimenta en su unificación última. ${ }^{6}$ Habría que pensar que, según Szlezák, la importancia de esta experiencia personal de Plotino es tal que imprime en su filosofía una marca indeleble que es preciso atender y apreciar en su justo valor. Gerson, por su parte, encabeza la tendencia contraria pues, a pesar del contundente tono místico de ciertos tratados

${ }^{5}$ Cada uno de estos dos elementos son interpretados, a su vez, de diferente manera por los estudiosos. Para un breve bosquejo de las interpretaciones diversas acerca de la relación de Plotino con la tradición que le precede véase Szlezák 1997, pp. 10-12. Para un esquema del modo en que los intérpretes han comprendido la mística plotiniana véase Perczel 1997, pp. 223-264, y Martino 2009, pp. 67-76.

${ }^{6}$ Véase Szlezák 1997, pp. 9 y ss. 
de las Enéadas, considera que la experiencia mística de Plotino está desconectada desde un punto de vista lógico de su filosofía entera. ${ }^{7}$

La complejidad y la tensión inherentes a la relación entre mística y exégesis en el pensamiento de Plotino, puestas de manifiesto no sólo en los tratados eneádicos, sino también en las interpretaciones dispares que han propuesto los especialistas, nos han impulsado a examinar esta relación en detalle. La finalidad de este artículo, pues, consiste en analizar el vínculo que estos dos "polos creativos" poseen en el pensamiento de Plotino. Para ello hemos acotado nuestro estudio de la exégesis plotiniana a un tópico, a saber, la henología o doctrina acerca de la trascendencia de lo Uno. En la siguiente sección, por lo tanto, revisamos aquellos elementos de la filosofía de Plotino que nos permitirían concluir que la henología eneádica tiene su origen en la exégesis plotiniana de sus predecesores. En una sección subsiguiente analizamos aquellos pasajes de las Enéadas que parecerían indicarnos que la doctrina de lo Uno tiene su origen en las experiencias trascendentes descritas por nuestro filósofo. Una vez examinados ambos "polos creativos" ofrecemos una interpretación posible acerca de su relación y funcionalidad en el pensamiento del filósofo neoplatónico.

\section{La polaridad exegética}

Lejos de considerar que Plotino ofrece una innovación radical en cuanto a los contenidos de su pensamiento, en el presente escrito defendemos el punto de vista según el cual nuestro filósofo se encuentra en una estrecha relación con los pensadores que le preceden. Tanto $\mathrm{Ph}$. Merlan ${ }^{8}$ como J. Whittaker ${ }^{9}$ han señalado, a nuestro entender con acierto, que durante el período medioplatónico reinaba una confusión con respecto al estatus del principio metafísico último y de su relación con la ousía y con el noûs, y que Plotino, si bien logra traer orden a la confusión, no parece hacer mucho más que eso. En consonancia con esta interpretación, en esta sección del artículo intentamos mostrar que la doctrina plotiniana de la trascendencia de lo Uno puede concebirse como el fruto de la exégesis de los sistemas metafísicos medioplatónicos que preceden a Plotino.

\footnotetext{
${ }^{7}$ Véase Gerson 1994, pp. 220 y ss.

${ }^{8}$ Véase Merlan 1963, p. 70.

${ }^{9}$ Véase Whittaker 1969, p. 104.
} 
Como es bien sabido, nuestro pensador desarrolla un sistema en el cual hay tres principios o hipóstasis: lo Uno, la Inteligencia y el Alma. Esta doctrina, afirma Plotino, no es nueva ni suya, sino que es la exégesis de la doctrina trinitaria de Platón que se encuentra en sus diálogos. ${ }^{10}$ Esta clase de autotestimonios en los cuales Plotino califica su pensamiento como exégesis de los antiguos es bien conocida por los lectores de las Enéadas. Pero el origen efectivamente platónico de la doctrina metafísica plotiniana es problemático, ya que en su interpretación Plotino no sólo reelabora y desarrolla nociones platónicas, sino que, además, recurre a doctrinas peripatéticas y estoicas. No analizamos ahora la relación directa e inmediata de la concepción plotiniana acerca de lo Uno con Platón. Este tema, por otra parte, ha sido estudiado en detalle por los especialistas, y Dodds, en un artículo ya clásico, ${ }^{11}$ demostró la estrecha conexión entre lo Uno plotiniano y el Parménides platónico. En este trabajo, por el contrario, examinamos el vínculo de la henología eneádica con la tradición posterior a Platón, en especial, con algunos autores medioplatónicos. La actitud sistematizadora de la obra platónica que evidencia este grupo de pensadores constituye un importante antecedente de la filosofía de Plotino, por lo cual su estudio no puede dejarse de lado cuando se quiere comprender el proceder exegético del pensador neoplatónico.

A continuación, intentamos mostrar que muchos filósofos medioplatónicos ya atribuían a Platón un sistema de tres principios al igual que Plotino, ${ }^{12}$ y que la doctrina de la trascendencia de lo Uno puede deducirse mediante una operación dialéctica del estado en que la reflexión metafísica se encontraba en el tiempo inmediatamente anterior a nuestro filósofo.

Alcinoo, escritor del siglo II d. C., sostiene en su Didaskalikós que Platón postula la existencia de tres principios: (1) la materia, (2) las Formas

${ }^{10}$ Cf. Plot. Enn. V.1.8.

11 Véase Dodds 1928, pp. 129-142.

12 Para un estudio detallado de la tradición medioplatónica véanse Dillon 1977 y Wallis 2002, pp. 29-36. Dillon (2002, pp. 93-94) sostiene que los orígenes precisos del sistema metafísico platónico trinitario son oscuros. Afirma, asimismo, que posiblemente fue formulado en respuesta a la crítica de Aristóteles según la cual Platón ignora la causa eficiente y parece creer que las Formas pueden actuar por sí mismas. El autor conjetura que debe haber aparecido con posterioridad a Jenócrates y que, de haber recibido la influencia del sistema estoico Dios-Logos-materia, no debe considerarse anterior a Antíoco de Ascalonia. 
y (3) Dios o Intelecto divino..$^{13}$ Esta concepción metafísica ternaria, a su vez, presenta una particularidad ya que las Formas son caracterizadas por el filósofo medioplatónico como inmanentes al Intelecto divino. ${ }^{14}$ Podríamos pensar, por lo tanto, que los tres principios descritos en el Didaskalikós son, estrictamente, dos, puesto que el Intelecto Divino y las Formas constituirían una sola entidad metafísica. Ahora bien, como ha indicado Merlan, ${ }^{15}$ encontramos en el Didaskalikós una contaminación de dos sistemas ontológicos diferentes. Este autor señala que en el tratado se sostiene, además, la existencia de una Inteligencia del cosmos que preside, a su vez, al Alma del cosmos. ${ }^{16}$ Esto nos podría hacer suponer que Alcinoo asimila su Inteligencia del cosmos al primer motor inmóvil del cosmos aristotélico. Sin embargo, agrega Merlan, en el Didaskalikós se postula la existencia de otro dios sobre el "dios aristotélico". El texto de Alcinoo, pues, atribuiría a Platón una concepción metafísica ternaria. Ésta estaría conformada, en primer lugar, por el primer Dios, que es, a su vez, Primera Inteligencia; en segundo lugar, por la (segunda) Inteligencia y, por último, por el Alma del cosmos. Esta tríada de principios estaría claramente anticipando los principios plotinianos, si bien el primer grado de la realidad es todavía caracterizado como una Inteligencia.

Otro pensador del siglo II d. C., llamado Apuleyo y autor del De Platone et eius dogmate, obra de carácter introductorio y didáctico semejante a la de Alcinoo, postula un sistema ontológico similar al que encontramos en el Didaskalikós. Este autor asevera que Platón afirma la existencia de tres principios: Dios, la materia y las Formas. ${ }^{17}$ Pero en el mismo tratado Apuleyo describe otra concepción metafísica: "Hay dos ousíai, que nosotros llamamos esencias [...]" - dice-. "Una de ellas se concibe mediante el pensamiento, $<$ mientras que $>$ la otra puede percibirse mediante los sentidos [...]." Y unas líneas más adelante afirma: "la primera sustancia o esencia es aquella (1) del primer Dios y también (2) de la Inteligencia y las Formas de las cosas, y (3) del Alma". ${ }^{18}$ Pode-

${ }^{13}$ Cf. Alcin. Did. IX.1.1-3.

14 Véase Loenen 1956, p. 314, y Martino 2010a.

15 Véase Merlan 1963, pp. 64-65.

${ }^{16}$ Cf. Alcin. Did. X.2.

${ }^{17}$ Cf. Apul. De Plat. I.5.

${ }^{18}$ Cf. Apul. De Plat. I.6.7-17. Ousías, quas essentias dicimus, duas esse ait [...], quarum una cogitatione sola concipitur, altera sensibus subici potest. [...] Et primae 
mos apreciar que esta clasificación de la ousía en inteligible y sensible le permite a Apuleyo introducir una segunda formulación de principios y considerarlos integrantes de la ousía inteligible. El sistema ternario que se concibe mediante el pensamiento está compuesto, según el pensador de Madura, por Dios, la Inteligencia junto con las Formas y, en tercer lugar, el Alma. Esta formulación ontológica ternaria también puede considerarse un antecedente de la tríada plotiniana. ${ }^{19}$

El carácter de manual didáctico ${ }^{20}$ que poseen tanto el Didaskalikós de Alcinoo como el De Platone de Apuleyo nos permite afirmar que ambos tratados evidencian el estado de los estudios e interpretación de la filosofía de Platón vigente en el tiempo en que fueron redactados ( $c a$. s. II d. C.). Plotino, por lo tanto, al escribir menos de un siglo más tarde, posee estos sistemas metafísicos como antecedente inmediato. Es evidente, por otra parte, que la tríada "primer Dios", concebido como una primera Inteligencia, otra "Inteligencia" y "Alma" constituyen, en cierto modo, la herencia que la tradición lega a Plotino y que él adopta en su pensamiento tras reelaborarla. ${ }^{21}$

Ahora bien, otro de los sistemas de principios que Plotino hereda es la concepción binaria de lo Uno y la Díada, sistema propio de lo que la crítica contemporánea identifica como las "doctrinas no escritas"22 de Platón. Estas, como es sabido, son descritas por Aristóteles como deri-

quidem substantiae uel essentiae primum deum esse et mentem formasque rerum et animam. Seguimos la traducción francesa de Beaujeu 2002, p. 65, y tomamos en cuenta la interpretación de Merlan 1963, p. 70, quien entiende, como nosotros, primum deum esse como "el primer dios", en lugar de "en primer lugar Dios...", cf. Camarero 1968, p. 28. Esto aclara en alguna medida la ambigüedad a que da lugar la enumeración de los principios y, en particular, si la Inteligencia y el primer Dios deben identificarse. En otro pasaje de la misma obra, Apuleyo se refiere a los primeros y más excelentes bienes - en plural (eximia, prima) - que hay para Platón, a los que llama Dios supremo e Inteligencia (deum summum mentemque illam, quam vov̂v idem uocat. Cf. De Plat. II.1). Estos, por lo tanto, son concebidos como principios diferentes y no se los identifica.

${ }^{19}$ Véase Merlan 1963, p. 70.

${ }^{20}$ Así ha llamado Dillon 2002, al Didaskalikós en su traducción y comentario al libro de Alcinoo.

${ }^{21}$ Para una comparación entre los principios del medioplatonismo y Plotino véase Merlan 1963, cap. II; Wallis 2002, pp. 16-36; Dillon 1977 y Whittaker 1969, pp. 91104.

22 Véase Kramer 1996, p. 143. 
vadas por Platón de los pitagóricos. ${ }^{23}$ Este conjunto de principios metafísicos, como veremos más adelante, también es adoptado por pensadores preplotinianos y constituye un ingrediente importante en la filosofía eneádica. ${ }^{24}$

Antes de analizar un texto de Plotino que ilustre la presencia de los sistemas recién aludidos en sus escritos, es necesario hacer una referencia a otro filósofo cuyas obras, según nos cuenta Porfirio en su biografía, eran leídas en las clases de su maestro. Nos referimos a Numenio de Apamea, quien realiza una síntesis de los dos sistemas metafísicos mencionados - ternario y binario - que guarda ciertas semejanzas con la plotiniana. ${ }^{25}$ Numenio sostiene un sistema metafísico dualista cuyos principios son, siguiendo la doctrina pitagórica, Dios o mónada y la materia o Díada. ${ }^{26}$ Pero, a su vez, el Dios numeniano es triple, puesto que posee tres instancias diferenciadas, que pueden caracterizarse mediante tres niveles distintos de actividad mental. ${ }^{27}$ La primera de estas es identificada con el Bien, que es, a su vez, Inteligencia primera, ${ }^{28}$ la segunda con el demiurgo ${ }^{29}$ que es, también, visión total de las Ideas, ${ }^{30}$ y, la tercera, con el Alma del cosmos. ${ }^{31}$ En este complejo sistema, Numenio ha integrado las dos ontologías, la binaria y la ternaria, como hará Plotino, pero reduciendo el sistema ternario a un subsistema del binario, lo cual es diferente del resultado de la combinación que encontramos en las Enéadas, tal como veremos a continuación.

Plotino, por su parte, mediante su procedimiento exegético y siguiendo el antecedente de Numenio, integra también estos dos sistemas de principios reuniendo en una composición peculiar el legado que la tradi-

${ }^{23}$ Cf. Arist. Metaph. 987a29-988a17.

${ }^{24}$ Véase, por ejemplo, Igal (Gredos) 1982, p. 43.

${ }^{25}$ Por este motivo, algunos de los contemporáneos de nuestro filósofo lo acusaron de haber plagiado a Numenio. Cf. Porph. Plot. 17. Para un breve análisis de las semejanzas y diferencias entre la metafísica plotiniana y numeniana véase Dodds 1957, pp. 16-24, y Wallis 2002, pp. 33-36.

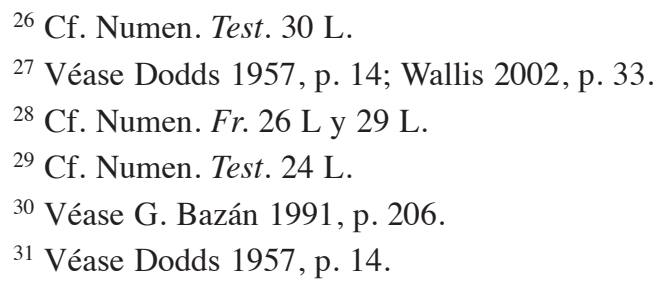


ción escolástica medioplatónica le hace llegar. Analicemos, a continuación, un pasaje del tratado V.4.

Si el progenitor fuera él mismo Inteligencia, (el generado) debería ser más deficiente que la Inteligencia pero próximo a la Inteligencia y semejante a ella. Pero puesto que el Progenitor está más allá de la Inteligencia, el generado es forzosamente Inteligencia.

- Pero ¿Por qué el progenitor no es Inteligencia, cuando la actividad (de ésta) es Intelección?

-Porque la Intelección, como ve al inteligible y se volvió hacia él, recibe de aquel su acabamiento, por así decirlo, es de por sí indefinida, como la vista; se hace definida por el Inteligible. Y por eso se ha dicho: 'de la Díada indefinida y del Uno <provienen> las formas y los números'. Porque esto es la Inteligencia. Por eso no es simple sino múltiple, exhibiendo composición - composición inteligible, sin embargo-, y viendo ya una multiplicidad. La Inteligencia es, pues, también ella inteligible, pero es además inteligente; por eso es ya dos cosas. Es además un inteligible distinto del Uno por ser posterior al Uno. ${ }^{32}$

En estas líneas, el filósofo Plotino condensa su diálogo con la tradición de la cual, al mismo tiempo, se aleja. Frecuentemente, los intérpretes entienden que la postulación plotiniana de la trascendencia de lo Uno respecto de la Inteligencia es una crítica a la teología de Aristóteles, ${ }^{33}$ quien, como es sabido, concibe al primer principio como un Intelecto divino que se piensa a sí mismo. ${ }^{34}$ Sin embargo, tal como hemos señalado, la metafísica de los autores medioplatónicos en general, e incluso de pitagorizantes como Numenio, también postula un primer principio al que identifica con una Inteligencia. La manifiesta identificación del primer principio con lo Uno y su caracterización como trascendente a la Inteligencia, por lo tanto, constituyen características distintivas del pensamiento plotiniano ${ }^{35}$ no sólo frente a Aris-

${ }^{32}$ Cf. Plot. Enn. V.4.2.1-12. Seguimos la traducción de Igal 1998, p. 91.

33 Considérense, a modo de ejemplo, Rist 1973, pp. 75-87, e Igal 1982, pp. 37-38.

${ }^{34}$ Cf. Arist. Metaph. XII.7.1072b19-21.

35 O’Cleirigh 1997, pp. 24. Estrictamente, la postulación de lo Uno como principio trascendente tanto al Ser como a la Inteligencia no es una novedad. Merlan 1963, pp. 70, afirma respecto de la "novedosa" trascendencia de lo Uno en Plotino: "Plotino pone orden en la confusión. Pero no parece que Plotino haga más que eso". Whittaker 1969, p. 102, en una misma línea, sostiene que la concepción del primer principio como tras- 
tóteles, sino también frente a los pensadores platónicos que le precedieron. ${ }^{36}$

En el pasaje recién citado, por otra parte, el interlocutor de Plotino pregunta: ¿por qué el progenitor no es la Inteligencia si la actividad de ésta es la intelección? Esta pregunta refleja fielmente la tradición que Plotino intenta superar puesto que contiene el supuesto de que la intelección es la actividad más elevada posible y, por lo tanto, la que debería identificar al Dios. Nuestro filósofo, por el contrario, responde mediante un análisis de la intelección y concluye que no es simple, sino múltiple, que exhibe composición, que es posible reconocer en ella un aspecto intelectivo y un aspecto inteligible y que, en consecuencia, no puede corresponder al primer principio. Asimismo, confrontando los dos sistemas metafísicos que hereda, Plotino toma conciencia de que no es posible identificar lo Uno con la Inteligencia divina, sino que reconoce la necesidad de subordinar la Inteligencia por ser (uni)múltiple a lo Uno, que debe ser verdaderamente simple. Esta subordinación de la Inteligencia, primer principio del sistema ternario, a lo Uno, principio supremo del sistema binario, es el procedimiento mediante el cual Plotino logra poner orden en la vacilación que imperaba en su tiempo en las concepciones metafísicas medioplatónicas.

Veamos, a título de ejemplo, un caso que nos ayude a ilustrar la confusión a la que nos referimos. Tal ejemplo lo encontramos en Aecio, doxógrafo del siglo I d. C., quien, a pesar de caracterizar a Dios como Uno, lo identifica, a su vez, con el ser y con la Inteligencia. ${ }^{37}$ Citemos un pasaje de este autor:

cendiendo al noûs era un tópico común en el período medioplatónico y que era ya disputado en la Antigua Academia. La confusión y el desacuerdo respecto de esta doctrina, sin embargo, es señalado por ambos autores como propio del período preplotiniano. Para un estudio de las fuentes preplotinianas que sostienen la doctrina de la trascendencia del primer principio véase Whittaker 1969, pp. 91-104.

36 Véanse Szlezák 1997, p. 69, y Bussanich 1988, pp. 9-10.

${ }^{37}$ Considérese a Orígenes, por ejemplo. Sobre este punto véase Igal 1982, p. 38; Rist 1964, p. 198; Whittaker 1969, pp. 91-104, y O'Cleirigh 1997, pp. 24-27. Numenio identifica a uno de sus principios con la mónada, que es, a su vez, un intelecto triple. Ni la totalidad de este principio ni su primer aspecto, asimilado con el Bien, son identificados con lo Uno (véase Dodds 1928, p. 132). Un autor que habría caracterizado lo Uno como más allá de la Inteligencia es el pitagórico Moderato de Gades (véase Wallis 2002, pp. 32-33). 
Platón afirma que Dios es lo Uno (

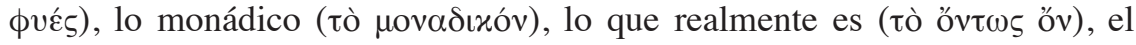
Bien ( $\tau \dot{\alpha} \gamma \alpha \theta o ́ v)$. Todos estos nombres muestran avidez por la Inteligencia. Dios, por consiguiente, es Inteligencia. ${ }^{38}$

Como estas líneas de Aecio ponen en evidencia, lo Uno, principio supremo del sistema binario, es asimilado al principio supremo del sistema ternario, la Inteligencia. Ahora bien, Plotino con justicia se pregunta, tal como vimos en su pasaje citado del tratado V.4, ¿si Dios o el progenitor es Uno, cómo es posible asimilarlo con la Inteligencia, si ésta es, por lo pronto, dual, en tanto que es inteligible y, a su vez, inteligente? Aquellos

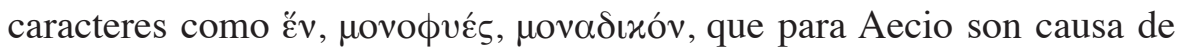
que Dios deba identificarse con la Inteligencia porque muestran "avidez" por ella, serían, en el caso de Plotino, la razón de por qué no es posible identificar al Dios con aquélla.

Podemos afirmar, incluso, que si la Inteligencia no puede asimilarse a lo Uno debido a que es dual por ser inteligible e inteligente, con menos razón todavía pueden identificarse ambos principios si consideramos que para Plotino las Formas constituyen el contenido de la Inteligencia. Las Formas son una multiplicidad de entidades inteligibles que por ser el contenido de la Inteligencia y, a su vez, los objetos de la intelección de aquélla ponen en evidencia el carácter múltiple de ésta o, en términos plotinianos, su carácter unimúltiple. La doctrina de la inmanencia de los inteligibles en la Inteligencia, cabe recordar, ya se encuentra formulada en el Didaskalikós, tal como señalamos al principio de esta sección, con lo cual tampoco constituye estrictamente una novedad del pensamiento eneádico.

Nuestra breve exposición de algunos aspectos de la metafísica medioplatónica nos permite formarnos una idea del estado de la exégesis de la filosofía de Platón en tiempos de nuestro filósofo y de los elementos tradicionales con los que Plotino trabaja a la hora de brindar su propia interpretación de la ontología platónica. Si reparamos en el modo en que el neoplatónico logra engranar en su pensamiento los principios metafísicos heredados, podemos apreciar sin dificultad en qué medida la trascendencia de lo Uno en Plotino es fruto de la exégesis y reelaboración de la ontología precedente.

${ }^{38}$ Cf. Stob. 1.1.29b, 58-60. 
Como afirmamos al comienzo de esta sección, la postulación de tres hipóstasis alinea a Plotino con la tradición que sostiene un sistema ternario. Sin embargo, el primer principio de la tríada plotiniana es lo Uno, primer principio del sistema binario, y no la Inteligencia, primera en la tríada medioplatónica. Plotino produce, como es evidente, una conjugación de los dos sistemas en la cual lo Uno resulta el principio supremo y la Díada, segundo principio del sistema binario, es asimilada a la Inteligencia. Las Formas, por otra parte, al ser consideradas por Plotino como inmanentes a la Inteligencia, constituyen junto con la Díada aspectos constitutivos de este segundo principio. Téngase en cuenta, asimismo, que ya Aristóteles había sostenido en su presentación de los principios platónicos que la Díada es el sustrato a partir del cual surgen las Formas. ${ }^{39}$ Podría decirse, pues, que la concepción plotiniana que entiende que "Inteligencia = Díada + Formas" es un resultado posible, sino necesario, de conjugar, por una parte, la doctrina presentada por Aristóteles que sostiene que las Formas surgen a partir de lo Uno y la Díada y, por otra, la tesis de la inmanencia de las Formas en el noûs, ya sostenida por Alcinoo. Consciente de este carácter múltiple de la Inteligencia, Plotino no concibe la posibilidad de identificarla con lo Uno, por lo que opta por postular que lo Uno es superior a aquélla.

La trascendencia de lo Uno respecto de la Inteligencia y de las Formas, como podemos apreciar, no es justificable sólo a partir de una lectura metafísica del Parménides platónico, sino también como el fruto del trabajo exegético que Plotino lleva a cabo sobre la ontología de la tradición interpretativa de Platón. El paso que nuestro filósofo da al considerar a lo Uno como trascendente a la Inteligencia, pues, es el resultado natural de su reflexión sobre la metafísica medioplatónica y no parece requerir de elementos de otro orden, menos aún místicos, para llevarse a cabo.

\section{La polaridad mística}

En la sección anterior hemos visto que la doctrina de la trascendencia de lo Uno es efectivamente deducible de la tradición metafísica heredada por Plotino. Es posible afirmar, sin embargo, que otra serie de discursos presente en las Enéadas podría inclinarnos a pensar que el origen de la doctrina de lo Uno, es más bien, místico.

${ }^{39}$ Cf. Arist. Metaph. I.6. 
Ahora bien, antes de dedicarnos al análisis de estos discursos, es necesario precisar qué entendemos por mística. Brisson, siguiendo a Hadot ${ }^{40}$ señala con razón que el significado etimológico de $\mu v \sigma \tau \iota x \omega \varsigma$ es "lo concerniente a los misterios", y que este término es utilizado, tanto por Plotino ${ }^{41}$ como por Porfirio, ${ }^{42}$ para designar un tipo de interpretación alegórica de mitos y de ritos. Esta acepción de ningún modo se refiere a las experiencias no conceptuales que encontramos en Plotino y que nosotros caracterizamos como místicas. ${ }^{43}$ Sin embargo, advertidos de los riesgos de anacronismo, ${ }^{44}$ consideramos junto con otros tantos autores ${ }^{45}$ que esta noción es perfectamente aplicable a un aspecto de la filosofía eneádica, en la medida en que se utilice con conciencia del significado que se le atribuye y de sus dificultades.

Entendemos, pues, por mística ${ }^{46}$ una clase de experiencia que provee al hombre, simultáneamente, de un modo de existir y un modo de conocer distintos y superiores niveles de la existencia y del conocimiento normales ${ }^{47}$ Ésta podría caracterizarse positivamente como "experiencia de lo absoluto" 48 o, mejor dicho, "experiencia absoluta", locución con la que entendemos que en ella no es posible distinguir un sujeto que ex-

${ }^{40}$ Véase Hadot 1980, pp. 459-465. Brisson 2007, pp. 453-459, sostiene: “el término mística... no puede ser utilizado para calificar la unión del alma con el primer Principio, designado como lo Uno o como el Bien".

${ }^{41}$ Cf. Plot. Enn. III.6.19.26.

${ }^{42}$ Cf. Porph. Plot. XV.2.

${ }^{43}$ Véase Hadot 1980, pp. 459-465.

${ }^{44}$ Hadot 1980, pp. 243-266, advierte sobre el riesgo de anacronismo, ya que estaríamos aplicando a Plotino esquemas que surgen del estudio de descripciones de experiencias místicas posthelénicas.

45 Son numerosos los autores que hablan de una mística plotiniana. Nombramos sólo algunos de ellos: Dodds 1928, pp. 141-142 y 1960, pp. 5-7; Armstrong 1940, pp. 29-35; Arnou 1967; Mamo 1976, p. 199; Hadot 1980, p. 245 y 1982-3, p. 463; Meijer 1992, p. 308; Beierwaltes 1995, pp. 146-147; Santa Cruz 1997, p. 357 y 2007, p. LXXX; Carone 1997, pp. 177-187; Ullman 2002, cap. X; Corrigan 2004, pp. 33-34; Sorabji 2006, p. 120; Brisson 2007, p. 464.

${ }^{46}$ Encontramos otra definición en Merlan 1963, p. 1: "Por definición consideramos que significa una doctrina que enseña que los momentos más elevados de la existencia del hombre son aquellos en los cuales se absorbe en lo que él cree que es lo divino [...] es una experiencia sui generis, que difiere de la experiencia humana común".

${ }^{47}$ Definición inspirada en Dodds 1968, p. 100.

${ }^{48}$ Reformulamos las palabras de Gardet, citadas por García Bazán 1978, p. 21. 
perimenta y un objeto experimentado. Por esta razón, tal experiencia es supraconceptual y supradiscursiva y no puede ser apresada con palabras ni conceptos sin traicionar su verdadera naturaleza.

En un sentido derivado, el término mística también puede ser utilizado para referirse a un género discursivo que remite a tal experiencia. A raíz de esta ambigüedad del término, podemos hablar tanto de una "experiencia mística" como de un "discurso místico". Si bien "discurso" y "experiencia" místicos no se implican entre sí necesariamente, en el caso de Plotino parecería que nos encontramos ante un filósofo que ha accedido a la experiencia ${ }^{49}$ y que ha desarrollado, a su vez, un género discursivo en relación con esta.

Si nos remitimos a la Vida de Plotino que Porfirio nos transmite junto con su edición de las Enéadas, encontramos algunas anécdotas valiosas para nuestra investigación. En su biografía, en efecto, Porfirio comenta que Plotino accedió a la experiencia mística numerosas veces. Transcribamos el pasaje.

Muchas veces, cuando se remontaba al Dios primero y trascendente con sus pensamientos y de acuerdo con las etapas trazadas por Platón en el Banquete, apareciósele [a Plotino] aquel Dios que carece de figura y de forma y está asentado sobre la Inteligencia y sobre todo lo inteligible. Yo, Porfirio, que estoy en el año sexagésimo octavo de mi vida, declaro haberme allegado a ese Dios y haberme aunado con él una sola vez. Pues bien, Plotino vio asomar la meta ya cercana, porque para él el fin y la meta es aunarse con el Dios omnitrascendente y allegarse con él. Cuatro veces, mientras estuve yo con él, alcanzó esta meta por una actividad inefable..$^{50}$

En estas líneas, Porfirio transmite importantes detalles que deben tenerse en cuenta. Por una parte, comenta que Plotino habría tenido efectivamente una serie de experiencias "místicas", que él mismo también habría

${ }^{49}$ En sus escritos, Plotino hace referencia a sus propias experiencias. Considérense, a modo de ejemplo, Plot. Enn. I.6.7.2-4; VI.9.9.40-43 y también IV.8.1.1-10.

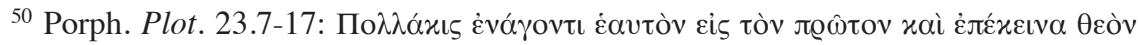

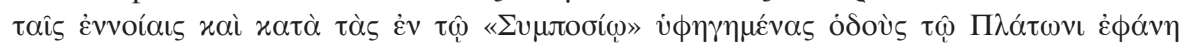

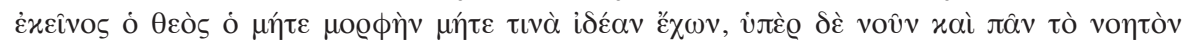

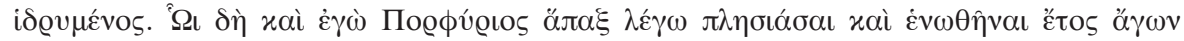

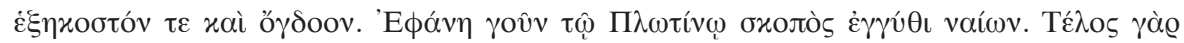

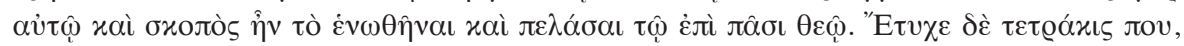

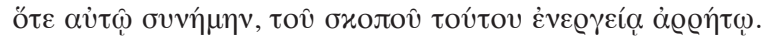


tenido una vez. Este testimonio, aparte de algunos pasajes de las Enéadas que podríamos considerar como alusiones a la propia experiencia de Plotino, nos permitiría corroborar que la mística plotiniana tiene su raíz en esta vivencia trascendente y que no es un desarrollo meramente especulativo o literario. ${ }^{51}$ Por otra parte, afirma que el filósofo alcanzó esta meta por una actividad inefable: se trata como es propio de toda experiencia mística, de una experiencia supradiscursiva y supraconceptual.

Pues bien, el carácter supraconceptual de la experiencia mística constituye una seria dificultad al momento de querer expresar esta vivencia, puesto que al intentar transmitirla mediante el lenguaje, se opera sobre ella, inevitablemente, una interpretación y un encuadre conceptual ${ }^{52} \mathrm{El}$ discurso místico plotiniano, así como todo discurso místico, ${ }^{53}$ puede implicar la experiencia, pero pertenece, forzosamente, al orden de la interpretación. Debido a esto, el segundo sentido del término mística que, como dijimos, se aplica a un género discursivo, siempre va a estar distanciado de la experiencia inefable de un modo insalvable y sólo podrá referirse a ella traicionando su naturaleza supraconceptual y reduciéndola a un esquema categorial. En el caso de las Enéadas, la presencia de un género discursivo místico es manifiesta y el tratado en el que su presencia es más evidente es VI.9, razón por la cual Porfirio ubica este escrito en último lugar al editar los textos de Plotino.

${ }^{51}$ Dodds 1968, p. 100, distingue, por un lado, a los místicos teóricos, quienes creen en la posibilidad de semejante unión, y, por otro, a los místicos practicantes, quienes creen haber tenido tales experiencias. En el primer grupo están incluidos los segundos, ya que los místicos practicantes creen en la posibilidad de semejante unión además de haberla experimentado, mientras que los teóricos, no por aceptar su posibilidad creen haberla experimentado. Podemos incluir a Plotino, por lo tanto, en el grupo de místicos practicantes.

52 Podríamos afirmar, incluso, que por el simple hecho de reflexionar y de traer nuevamente a la conciencia tal experiencia, esta es interpretada. Deberíamos hablar, por tanto, de una "experiencia pura" si queremos indicar el momento y estado de trance extático, pero al estudiar la mística plotiniana nos limitamos a sus discursos, por lo cual tal distinción resulta innecesaria. Para un desarrollo de los múltiples factores que constituyen la experiencia mística, véase Panikkar 2005, pp. 131-161. En relación con la inmediatez de la aprehensión mística en Plotino y su distanciamiento del lógos véase, a modo de ejemplo, Plot. Enn. VI.9.4.1-10 y V.3.17.25-28. Para un estudio detallado de la relación entre experiencia mística y discurso en Plotino véase Martino 2010b, pp. 67-76.

${ }^{53}$ Sobre la relación entre experiencia mística y discurso, véase Panikkar 2005. 
Así, el discurso místico plotiniano es complejo y es posible distinguir en él diferentes especies. En primer lugar, se podría reconocer un discurso metafórico con el cual nuestro autor retrata la experiencia mística mediante imágenes. Esta primera clase puede ser caracterizada como "atomizante", pues tiende a brindar una serie de representaciones que no están, necesariamente, conectadas entre sí, ni vinculadas con la metafísica plotiniana de un modo inmediato. Algunas de las metáforas utilizadas por Plotino e incluidas en esta especie discursiva son la de coincidencia de centros ${ }^{54}$ las metáforas eróticas, entre otras. En segundo lugar, encontramos un discurso "interpretativo integrador", mediante el cual Plotino relaciona directamente la experiencia mística con su sistema metafísico, a raíz de lo cual podríamos considerar que se trata de una doctrina mística. $\mathrm{Y}$, en tercer lugar, es posible identificar, a su vez, una especie discursiva que busca reducir al mínimo la imposición de categorías conceptuales sobre la vivencia inefable. Esta última clase parece ser el fruto de una retórica conciente de las limitaciones del lenguaje para apresar y transmitir la experiencia trascendente, por lo cual más que intentar interpretarla diciendo lo que es, procura expresar lo que la experiencia mística no es.

En este trabajo no analizamos la primera especie de discursos místicos, pues esta ya ha sido estudiada en detalle por los especialistas. ${ }^{55}$ Examinamos, más bien, la segunda y tercera especies. Citemos, a continuación, un pasaje en el cual Plotino recurre a la tercera clase identificada.

El vidente mismo era una sola cosa con lo visto - por lo que no sería 'lo visto' sino 'lo aunado'. [...] Ahora bien, él mismo era uno pues no tenía en sí diversidad alguna ni con respecto a sí mismo ni con respecto a otras cosas. Pues nada se movía en él: no <se movía> el ánimo (ningún deseo de otra cosa se hacía presente en él habiendo ascendido), pero tampoco <se movía $>$ la razón ni intelección alguna, ni él mismo en absoluto <se movía $>$, si hay que decir esto. Sino que, tras ser como arrebatado o estar como endiosado, se quedó en soledad y en estado de quietud serena, sin inclinarse en su esencia a ninguna parte ni volverse sobre sí mismo, completamente fijo y devenido, por así decirlo, estabilidad. ${ }^{56}$

\footnotetext{
54 Plot. Enn. VI.9.8.
}

55 Para un análisis orientativo véase, por ejemplo, MacKenna 1969, pp. lxiv-lxx; Meijer 1992, p. 229; Mazur 2009, pp. 67-83.

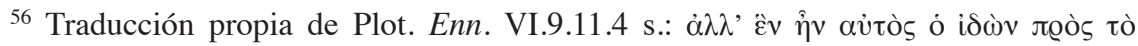

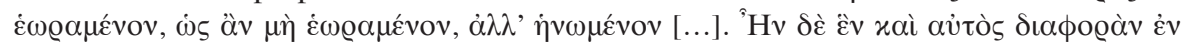


Este pasaje, a nuestro entender, evidencia claramente un discurso en el cual se intenta describir una experiencia a la cual no le caben caracteres positivos de ninguna clase. Pone de manifiesto, asimismo, la conciencia de Plotino de que cualquier atribución estaría traicionando la naturaleza pura, por así decirlo, de la experiencia mística ${ }^{57}$ Incluso la utilización de atributos positivos como "estado de quietud" o "soledad" se entienden, en este contexto, como un refuerzo de los atributos negativos "ausencia de movimiento" o "ausencia de alteridad". ${ }^{58}$ Podemos afirmar que esta descripción es la más adecuada de las posibles para referirse a la experiencia, pues le impone un grado mínimo de conceptualización. Esta especie discursiva, entonces, representa todo lo que es posible acercarse a la experiencia mística mediante el discurso sin involucrarse con una doctrina o interpretación.

Además, otros pasajes eneádicos nos ofrecen discursos místicos mucho más cargados de interpretación. El esfuerzo por volver inteligible esta experiencia hace que Plotino le adose un sentido que ella en sí misma no posee, el de su pensamiento metafísico. Consideramos que esta clase de discursos constituye la doctrina mística plotiniana que consiste en la reflexión del filósofo sobre su experiencia inefable mediante las categorías de su ontología. Esta doctrina corresponde a lo que hemos caracterizado como discurso "interpretativo integrador" sobre la experiencia mística debido a que brinda una interpretación de la experiencia que la integra a su sistema metafísico. Transcribamos un pasaje que nos ayude a captar esto con claridad.

Hay que tornarse Inteligencia, confiar la propia alma a la Inteligencia e instalarse en ella para que admita en plena vigilia aquello que la Inteligencia ve. Hay que contemplar lo Uno por la Inteligencia, sin añadir ninguna sensación, ni admitir en aquello nada proveniente de la sensación; por el

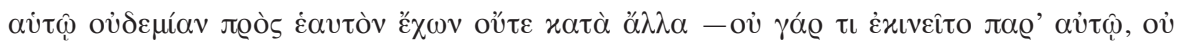

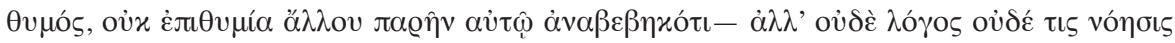

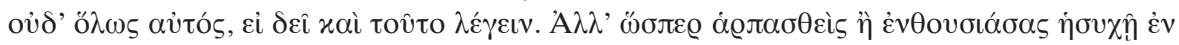

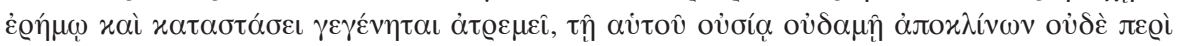

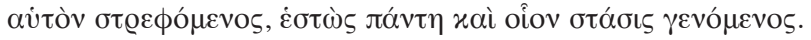

${ }^{57}$ En relación con la conciencia de Plotino de las dificultades que implica la interpretación de las experiencias místicas, cf. Plot. Enn. VI.9.3.52.

${ }^{58}$ En otros pasajes, en efecto, Plotino habla de lo Uno como anterior al reposo. Cf. Plot. Enn. VI.9.3.44-45. 
contrario, hay que contemplar lo más puro con la pura Inteligencia y con lo primero de la inteligencia. ${ }^{59}$

Este segundo pasaje, a diferencia del anterior, caracteriza la experiencia mística mediante términos positivos que implican, a su vez, una metafísica. Es evidente que este discurso enmarca la vivencia inefable en un sistema conceptual, por lo cual, si bien parece estar refiriéndose a la experiencia, corresponde a lo que llamamos "doctrina mística". En ella, la presencia del Alma, de la Inteligencia y de lo Uno es manifiesta, así como las relaciones que el hombre debe establecer con estas realidades para poder acceder a la experiencia mística. Ahora bien, es preciso recordar que esta clase de interpretaciones atenta contra la comprensión de que la experiencia es inmediata, en el sentido de que carece de toda mediación conceptual y discursiva, y que nos induce a creer que ella posee, efectivamente, los caracteres positivos y los atributos con los que se la interpreta.

Trazadas estas distinciones entre experiencia y discursos místicos, entre los cuales encontramos, a su vez, a la doctrina, resta que examinemos, por una parte, la función que la mística cumple en el pensamiento plotiniano y, por otra, la relación de ésta con la exégesis. Dejamos el examen de este último punto para la sección siguiente y desarrollamos, a continuación, algunos aspectos del primero de ellos. Citemos un último pasaje de las Enéadas para ilustrar nuestro punto de vista.

Mas hablamos y escribimos para conducir hacia él y para despertar de las palabras a la contemplación, como indicándole el camino al que desea contemplar. Pues la enseñanza es solo del camino y de la marcha a seguir, mas la contemplación es ya obra de aquel que ha deseado ver. ${ }^{60}$

En estas líneas, Plotino explica que el propósito del discurso místico, de la enseñanza sobre lo Uno y sobre la contemplación que es posible

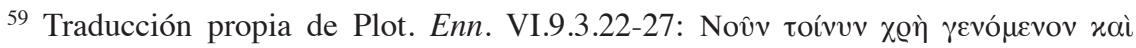

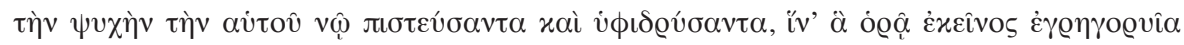

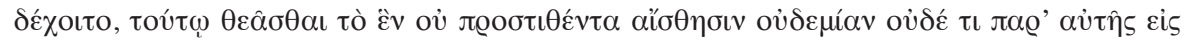

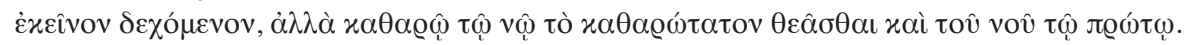

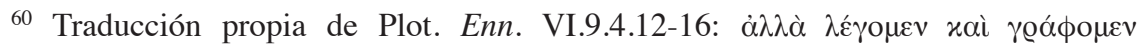

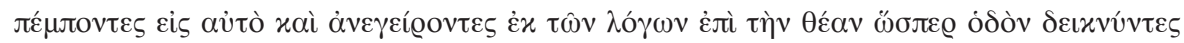

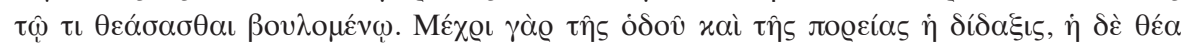

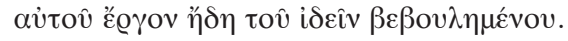


obtener de aquél, es la experiencia mística. No se trata, pues, de una inquietud meramente expresiva. Mediante esta clase de discursos, por el contrario, Plotino abre su propia experiencia íntima y trascendente a los otros hombres. Con ellos, el filósofo procura, por un lado, brindar una cierta imagen inteligible del bien al que los hombres deben tender y, por otro, despertar el anhelo por encaminarse hacia aquello. Los discursos místicos, tal como Plotino afirma en el pasaje citado, también son indicaciones del sendero que debe recorrerse para llegar al final del camino. Los discursos místicos, en fin, vuelven inteligible lo inefable, gracias a lo cual quien ha accedido a una experiencia que carece de toda determinación puede describirla a los otros hombres con el fin de que ellos también despierten a la contemplación y obtengan la experiencia por sí mismos. Tal finalidad, sin embargo, no podría ser cumplida si el punto de partida de los discursos místicos plotinianos no fuera su propia experiencia trascendente. Plotino, en efecto, afirma que puede señalar el camino porque él mismo lo ha recorrido y que puede caracterizar la vivencia de unión con lo Uno porque él mismo la ha experimentado. ${ }^{61}$ Consideremos, al menos de modo hipotético, la incidencia de las enseñanzas de Plotino sobre el hecho de que Porfirio lograra, él también, aunarse con lo Uno al menos una vez. ${ }^{62}$

Ahora, al tener el discurso místico una finalidad persuasiva, exhortativa y anagógica implica, a su vez, la experiencia mística del que indica el camino. Podemos apreciar, pues, que la relación entre experiencia y discurso místicos resulta ser de implicación mutua, en la medida en que la experiencia propia de Plotino se revela como condición necesaria para su discurso pero este, a su vez, es presentado como la instrucción que permitirá a quienes son mentados por él a que lleguen, por sí mismos, a la experiencia, final del camino. Entonces, la función creativa de la mística plotiniana es doble: cada uno de los modos en que la entendemos, es decir, tanto el discurso como la experiencia, posee su impulso generador: la experiencia engendra el discurso ${ }^{63}$ y el discurso posibilita la experiencia.

${ }^{61}$ Cf. Plot. Enn. VI.9.9.40-61.

${ }^{62}$ Cf. Porph. Plot. 23.13.

${ }^{63}$ Sobre el poder generador de discursos que posee el encuentro con lo Uno, cf. VI.9.7.16-29. 


\section{Propuestas para una interpretación de la relación entre la mística} y la exégesis en la filosofía plotiniana

En la sección anterior hemos visto que la mística eneádica incluye, por una parte, la experiencia inefable a la que Plotino habría accedido en más de una oportunidad y hacia la que exhorta a sus lectores y, por otra, los discursos que aluden a aquélla. Entre estos discursos, a su vez, identificamos una especie que consiste en una interpretación de la experiencia constituyendo una doctrina.

Ahora bien, en nuestro análisis de la experiencia y del discurso místicos sugerimos que la relación que hay entre ellos es circular en tanto que, para Plotino, la experiencia se revela como condición necesaria para el discurso místico, pero éste, a su vez, es presentado como la instrucción que permite que otros obtengan, por sí mismos, la experiencia. Resta examinar, pues, la relación entre mística y exégesis en la filosofía de Plotino.

Al caracterizar la experiencia mística sostuvimos que ésta posee un carácter inmediato, en el sentido de que carece de toda mediación conceptual y discursiva. Afirmamos, asimismo, que, al presentar su doctrina mística, Plotino se vale de las categorías propias de su sistema metafísico con la finalidad de interpretar la experiencia mística y tornarla inteligible. El papel de la exégesis en el marco de la mística, pues, es evidente. El sistema metafísico al que Plotino arriba mediante la exégesis de los antiguos le provee el marco conceptual para expresar lo inexpresable y comprender lo que se encuentra más allá de la comprensión intelectual. Desde el punto de vista de la mística, por lo tanto, la exégesis metafísica que Plotino realiza de sus antecesores cumple un papel instrumental, en la medida en que le proporciona los conceptos que le permiten deslizarse de la vivencia mística inefable al discurso místico inteligible, es decir, de la experiencia a la doctrina. ${ }^{64}$

Pero es posible, asimismo, considerar la relación desde otro punto de vista. Como vimos en la primera sección de este artículo, la ontología plotiniana y, en especial, la doctrina de la trascendencia de lo Uno pue-

${ }^{64}$ Podemos afirmar que la exégesis de la ontología de los antiguos no es el único instrumento con el cual Plotino tornará lo inefable en discurso. Pensemos, por ejemplo, en las metáforas correspondientes a lo que identificamos con la especie "atomizante" de discurso místico. Ahora bien, al no encontrarse esta última especie discursiva en una relación inmediata con la exégesis plotiniana de la metafísica heredada no lo analizamos en este trabajo. 
den considerarse como el resultado de la reflexión de Plotino sobre la tradición metafísica platónica. Y al asociar la mística a su pensamiento metafísico, Plotino logra enriquecer la exposición de su ontología. Gracias al condimento aportado por la doctrina mística, la ontología deja de ser un terreno exclusivo del conocimiento teórico, para tornarse en "una presencia más poderosa que la ciencia", ${ }^{65}$ a la cual el hombre puede acceder experimentando íntimamente y por sí mismo los grados de la realidad que Plotino postula en su exégesis del pensamiento precedente. Desde esta perspectiva, pues, la mística cumple un papel instrumental respecto de la exégesis en la medida en que le permite a Plotino deslizarse del discurso inteligible a la experiencia inefable. La relación entre el discurso metafísico que surge de la exégesis de sus antecesores y la mística parece otorgarle a la ontología especulativa plotiniana la fuerza de una comprobación, en la medida en que el hombre puede experimentar los grados de la realidad descritos en su filosofía.

Es necesario tener en cuenta, no obstante, que cuando afirmamos que la "mística" parece corroborar la "metafísica" estamos utilizando aquel término para referirnos a la "doctrina mística" tal como la definimos anteriormente. La experiencia mística, de hecho, por ser supraconceptual e inefable no puede implicar ni remitir con necesidad a ningún sistema de conceptos metafísicos en particular. La doctrina mística, por el contrario, sí remite al sistema metafísico, ya que es producto de la articulación entre la experiencia y la ontología. Pero considerar que la doctrina mística es una comprobación de la ontología es un error, ya que de hacerlo caemos en una falacia de petición de principio. En ese caso, estaríamos tomando la exégesis plotiniana de la metafísica precedente como punto de partida para una interpretación de la experiencia mística, para luego sostener que la mística corrobora la exégesis plotiniana.

Podemos afirmar, pues, que la mística posee en relación con la exégesis, simplemente, un valor persuasivo. Asimismo, podemos creer que la mística proveerá la ilusión de funcionar como una verificación de la exégesis. Esta ilusión, finalmente, sólo puede ser desarticulada en la medida en que distingamos con claridad entre experiencia mística y doctrina mística. Cabe aclarar, sin embargo, que no resulta sencillo trazar esta distinción debido a que la más mínima expresión sobre la experiencia mística implica, en algún grado, interpretación.

${ }^{65}$ Plot. Enn. VI.9.4. 
Aún así, hay un elemento importante que debe tenerse en cuenta: la experiencia mística plotiniana es supraintelectual. Esto nos lleva a la necesidad de plantear un estrecho paralelismo entre la supraintelectualidad de lo Uno y la de la experiencia trascendente. Esta correspondencia es más que significativa y provee mayor fuerza al planteo ontológico plotiniano. Sin embargo, la aludida correlación no anula el hecho de que la propuesta metafísica plotiniana pertenece al plano discursivo, mientras que la experiencia mística es supradiscursiva. En todo caso, podemos afirmar que el carácter supraconceptual y supradiscursivo tanto de la experiencia mística como de lo Uno refuerzan la interpretación de la experiencia en términos de la metafísica eneádica. ${ }^{66}$

\section{Conclusiones}

Nuestras reflexiones acerca de la función que la mística y la exégesis cumplen en la filosofía de Plotino nos han llevado a sugerir una interpretación acerca de la relación entre estos dos elementos. La visión que hemos propuesto, a su vez, nos permite reconsiderar algunos aspectos de las posiciones de Gerson y de Szlezák acerca de este tema.

Examinamos, en primer lugar, dos sistemas metafísicos de inspiración platónica sostenidos por pensadores que anteceden a Plotino. El ternario, por una parte, constituido por el Alma del mundo, el Intelecto del mundo y Dios o el primer Intelecto, aparece en las obras de Alcinoo y de Apuleyo. El esquema binario, por otra parte, que incluye a lo Uno y a la Díada, es atribuido a Platón nada menos que por Aristóteles. Tanto Aecio como Numenio son un ejemplo de pensadores que con anterioridad a Plotino amalgaman, cada uno a su modo, ambos sistemas. El análisis llevado a cabo en la primera sección del artículo ha pretendido, pues, poner de manifiesto que la metafísica eneádica y, en especial, la doctrina de la trascendencia de lo Uno tienen su origen en la exégesis plotiniana de la ontología precedente.

En segundo lugar, analizamos el discurso místico eneádico y sostuvimos que tiene su fuente de inspiración en la propia experiencia mística de Plotino, por lo cual indicamos que es preciso distinguir entre experiencia y discurso dentro de la mística plotiniana. Señalamos, a su vez, diferen-

${ }^{66}$ La experiencia mística bien podría haberse interpretado con otras categorías conceptuales que remitan, de todos modos, a lo supraconceptual. 
tes clases del discurso místico y afirmamos que nuestro filósofo recurre a su pensamiento metafísico para elaborar aquella clase que llamamos "doctrina mística". Esto nos permitió concluir que la doctrina mística es secundaria a la exégesis plotiniana de la ontología precedente.

Hemos visto, pues, que, al surgir a partir de la exégesis de la ontología precedente, el sistema metafísico plotiniano no requiere necesariamente de la mística. Podríamos pensar, incluso, que un esquema tal podría haber sido planteado por otro pensador que, sin tener ninguna experiencia trascendente, siguiera el mismo camino exegético que describimos en la primera sección. Nuestro análisis nos llevó a reconocer, asimismo, que en último término la experiencia mística por sí misma no puede corroborar ninguna metafísica especulativa determinada puesto que trasciende toda especulación y es previa a toda conceptualización. Desde esta perspectiva, estaríamos dispuestos a concederle a Gerson que su interpretación es en alguna medida correcta. Si bien no consideramos que la mística está lógicamente desconectada de la filosofía plotiniana, tal como él afirma, creemos que no debe buscarse el origen de la metafísica eneádica en la mística.

Es preciso señalar, sin embargo, que la filosofía plotiniana excede ampliamente su examen y exégesis de la metafísica platónica en la medida en que su fin último no es meramente especulativo. La concepción plotiniana de la filosofía, por el contrario, no consiste en teoremas y reglas ni en simples proposiciones, sino que es la búsqueda de inteligir una verdad que se da en el terreno noético y cuyo fundamento es concebido como una realidad trascendente al ámbito noético e incluso óntico. ${ }^{67}$ En este sentido, la filosofía eneádica busca transformar la disposición interna del hombre de modo que la existencia de una realidad suprasensible, origen y fin de lo sensible, sea garantizada por la íntima certeza que provee la experiencia mística. La filosofía plotiniana, podemos decir, alcanza su objetivo en la persona de Plotino, si admitimos que él logró acceder al fundamento suprasensible de la realidad, y también en Porfirio si tomamos en cuenta su testimonio de que también él alcanzó la experiencia inefable. ${ }^{6}$ Podríamos pensar que el pensamiento plotiniano es aún más fértil si consideramos, como se ha dicho, que Plotino es el padre de la

${ }^{67}$ Cf. Plot. Enn. I.3.5.

${ }^{68}$ Cf. Porph. Plot. 23. 
mística occidental. ${ }^{69}$ Tomada bajo esta perspectiva, la mística plotiniana es un ingrediente fundamental en la filosofía eneádica en la medida en que, para Plotino, una propuesta metafísica que no ha sido incorporada mediante la certeza íntima que provee la experiencia mística tiene poco o ningún valor filosófico. A raíz de lo afirmado, creemos que es preciso matizar el punto de vista de Gerson quien sostiene la desconexión entre la mística y la filosofía de Plotino y que la posición de Szlezák puede iluminar nuestra comprensión del pensador neoplatónico. Szlezák afirma, de hecho, que la unificación con lo Uno es el fin que Plotino presenta al filósofo,${ }^{70}$ por lo que pensamos, en consonancia, con este autor, que la experiencia mística - y el discurso anagógico que surge del contacto entre la experiencia y la exégesis - debe considerarse como el coronamiento de la filosofía expuesta en las Enéadas. Ahora bien, afirmar que la experiencia mística es el coronamiento de la filosofía eneádica no implica que aquélla corrobore la propuesta ontológica plotiniana, tal como intentamos demostrar en la segunda sección del artículo.

Finalmente, consideramos que podría haber otro camino legítimo para repensar la relación entre exégesis y experiencia trascendente, sin necesidad de recurrir a la doctrina mística. Para establecer y determinar la naturaleza de esta relación sería necesario, según creemos, partir de un análisis de la psicología plotiniana en estrecha relación con su metafísica. Estudiar esta propuesta en el marco de la filosofía de Plotino correspondería a una nueva investigación.

\section{BIBLIOGRAFÍA}

\section{Fuentes}

APUlEyo, Tratados filosóficos. Traducción, notas y estudio preliminar de A. Camarero, México, Universidad Nacional Autónoma de México, 1968.

Numenio, Fragmentos y testimonios. Traducción, notas y estudio preliminar de F. García Bazán, Madrid, Gredos, 1991.

Plotino, Eneadas, 3 vols. Introducciones, traducción y notas de J. Igal, Madrid, Gredos, 1982-2006.

_., Eneadas, Textos esenciales. Traducción, notas y estudio preliminar de M. I. Santa Cruz y M. I. Crespo, Buenos Aires, Colihue, 2007.

PLotinus, The Enneads. Translated by S. Mackenna, London, Faber, 1969.

${ }^{69}$ Rist 1967, p. 213.

${ }^{70}$ Véase Szlezák 1997, p. 9. 
Estudios

Armstrong, A. H., The Cambridge History of Later Greek and Early Medieval Philosophy, Cambridge, Cambridge University Press, 1967.

__, Introducción a la Filosofía Antigua, Buenos Aires, EUdEBA, 1973.

__, The Architecture of the Intelligible Universe in the Philosophy of Plotinus: An Analytical and Historical Study, Cambridge, Cambridge University Press, 1940 .

__, "The Apprehension of Divinity in Plotinus", en R. Baine Harris (ed.), The Significance of Neoplatonism, Norfolk, Old Dominion University, 1976, pp. 187-198.

Arnou, R., Le Désir de dieu dans la philosophie de Plotin, Roma, Presses de l’Universtité Grégorienne, 1967.

BeIERwaltes, W., Autoconoscenza ed esperienza dell'unità: Plotino, Enneade V 3, Roma, Vita e Pensiero, 1995.

Brisson, L., "Pode-se Falar de União Mística em Plotino?”, Kriterion, 116, 2007, pp. 453-466.

Bussanich, J., The One and its Relation to Intellect in Plotinus, Leiden, Philosophia Antiqua 49, 1988.

Carone, G. R., "Mysticism and Individuality: a Plotinian Paradox", en J. Cleary (ed.), The Perennial Tradition of Neoplatonism, Leuven, Leuven University Press, 1997, pp. 177-187.

Corrigan, K., Reading Plotinus, A Practical Introduction to Neoplatonism, Indiana, Purdue University Press, 2004.

Dillon, J., The Middle Platonists, New York, Cornell University Press, 1977. , Alcinous, the Handbook of Platonism, Oxford, Clarendon Press, 2002.

DodDs, E. R., "The Parmenides of Plato and the Origin of the Neoplatonic 'One", Classical Quarterly, 22, 3/4, 1928, pp. 129-142.

__, "Tradition and personal achievement in the philosophy of Plotinus", Journal of Roman Studies, 50, 1960, pp. 1-7.

__, Numenius and Ammonius, en Les Sources de Plotin, Ginebra, Foundation Hardt, 1957.

__, Paganos y cristianos en una época de angustia, Madrid, Ediciones Cristiandad, 1968.

Eon, A., "La notion plotinienne d'exégèsse", Revue Internationale de Philosophie, 92, 2, 1970, pp. 252-289.

García BazÁn, F., "El lenguaje de la Mística”, Escritos de Filosofía, 1, 1978, pp. 17-28.

Gerson, L. P., Plotinus, London, Routledge, 1994.

Hadot, P., "Les Niveaux de Conscience dans les États Mystiques selon Plotin", Journal de Psychologie, 2-3, 1980, pp. 243-266.

__, "Histoire de la Pensée Hellénistique et Romaine", Annuaire du Collège de France, 1982-1983, pp. 459-465. 
Krämer, H., Platón y los fundamentos de la metafísica, Caracas, Monte Avila, 1996.

Loenen, J. H., “Albinus' Metaphysics: An Attempt at Rehabilitation: I. The Inner Consistency and the Original Character of Albinus' Interpretation of Plato", Mnemosyne, Fourth Series, 9, 4, 1956, pp. 296-319.

Mamo, P., "Is Plotinian Mysticism Monistic?", en R. Baine Harris (ed.), The Significance of Neoplatonism, Norfolk, Old Dominion University, 1976, pp. 199-215.

MARTino, G., "La noción de contemplación ( $\theta \varepsilon \omega \varrho i ́ \alpha)$ y de vida contemplativa (ó

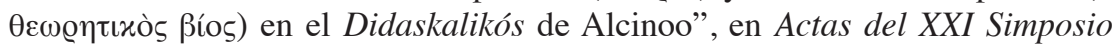
Nacional de Estudios Clásicos, Santa Fe, Facultad de Humanidades y Ciencias, 2010a.

_. "La mística plotiniana: experiencia, doctrina e interpretación", Revista Archai, 5, 2010b, pp. 67-76.

Mazur, Z., "Having Sex with the One: Erotic Mysticism in Plotinus and the Problem of Metaphor", en P. Vassilopoulou y S. R. L. Clark (eds.), Late Antique Epistemology: Other Ways to Truth, Houndmills, Basingstoke, Palgrave Macmillan, 2009, pp. 67-83.

Meijer, P. A., Plotinus on the Good or the One, An Analitical Commentary, Amsterdam, Gieben, 1992.

Merlan, P., Monopsychism, Mysticism, Metaconsciousness, La Haya, Martinus Nijhoff, 1963.

O'CleIRIGH, P., “Theology in Origen and Plotinus”, en J. Cleary (ed.), The Perennial Tradition of Neoplatonism, Leuven, Leuven University Press, 1997, pp. 19-28.

O’Meara, D., Plotinus, An Introduction to the Enneads, Oxford, Clarendon Press, 1993.

PANIKKAR, R., De la Mistica. Experiencia plena de la vida, Barcelona, Herder, 2005.

Perczel, I., "L' 'Intellect Amoureux' et l' 'Un qui est'. Une doctrine mal connue de Plotin", Revue de Philosophie Ancienne, XV, 2, 1997, pp. 223-264.

Rist, J. M., Eros and Psyche. Studies in Plato, Plotinus and Origen, Toronto, University of Toronto Press, 1964.

_., "The One of Plotinus and the God of Aristotle", Review of Metaphysics, 27, 1, 1973, pp. 75-87.

_. Plotinus, The Road to Reality, Cambridge, Cambridge University Press, 1967.

Runia, D. T., "A Brief History of the term 'Cosmos Noétos' from Plato to Plotinus", en J. Cleary (ed.), Traditions of Platonism. Essays in honour of John Dillon, Aldershot, Ashgate Publishing Limited, 1999.

Santa Cruz, M. I., "Plotino y el Neoplatonismo", en Carlos García Gual (ed.), Historia de la filosofía antigua, vol. 14 de la Enciclopedia Iberoamericana de Filosofía, Madrid, Trotta, 1997, pp. 339-361.

_., "Modos de conocimiento en Plotino", Estudios de Filosofía, 34, 2006, pp. 201216. 
SorabJi, R., Self, Ancient and Modern Insights about Individuality, Life and Death, Chicago, The University of Chicago Press, 2006.

SzLEZÁk, T., Platone e Aristotele nelle dottrina del Nous di Plotino, Milano, Vita e Pensiero, 1997.

Ullmann, R. A., Plotino, Um estudo das Enéadas, Porto Alegre, EDIPUCRs, 2002. Wallis, R. T., Neoplatonism, London, Bristol Classical Press, 2002.

WhitTAKer, J., "Epekeina nou kai ousias", Vigiliae Christianae, 23, 2, 1969, pp. 91-104. 